\title{
One-pot preparation of surface modified boehmite nanoparticles with rare-earth cyclen complexes $\dagger$
}

\author{
Estefanía Delgado-Pinar, ${ }^{a}$ Juan C. Frías, ${ }^{* b}$ Luis J. Jiménez-Borreguero, ${ }^{c}$ M. Teresa Albelda, ${ }^{b}$ \\ Javier Alarcón ${ }^{* a}$ and Enrique García-España ${ }^{* b}$
}

Received (in Austin, TX, USA) 27th March 2007, Accepted 18th May 2007

First published as an Advance Article on the web 18th June 2007

DOI: $10.1039 / \mathrm{b} 704650 \mathrm{~b}$

We report on the one-pot synthetic procedure of cyclen derivatives bearing three acetate groups attached on boehmite nanoparticles, the complexing capabilities of these inorganicorganic hybrid materials with rare earth cations, and the behaviour as contrast agents or fluorescence probes.

There is much interest in the functionalisation of nanoparticles with organic components for a wide variety of goals. ${ }^{1}$ The good dispersability in organic media of such surface modified nanoparticles by organic molecules offers many possibilities in important areas of chemistry such as analytical chemistry, catalysis and medical research. ${ }^{2}$ Although a wide variety of nanoparticle supports have been reported, most of these concern silica, gold or II-VI semiconductors. ${ }^{3}$ We have recently shown the possibilities of new sensing systems based on nano-sized boehmite as support of indole- or naphthalene-polyamines. ${ }^{4,5}$ This type of sensing system is based on the phenomenon of photoinduced electron transfer (PET). Furthermore, the use of boehmite nanoparticles as support presents additional advantages such as, the possibility to make fluorescence emission studies in pure water with little scattering and the recovering of the sensor system after using.

Extraction of rare earth cations from solutions of nuclear fuel wastes are of crucial importance for both the further conversion of the waste into a wasteform by solidification, embedding or encapsulation and for possible reprocessing. The ability of acetates and phosphates side arms in polyazamacrocycles or linear polyamines to bind rare earth metal cations is well known. ${ }^{6}$ However, as far as we know there are no reports using these ligands in a chemical system to extract these radioactive rare earth cations from aqueous solutions and be able to recover the extractor for further reusing. We demonstrate here that the system formed by the cyclen molecule with acetate-containing groups bonded to three nitrogen atoms can be attached by alkoxysilanes to boehmite nanoparticles. This opens up the possibility of the development of rare earth cations extractor chemical devices from aqueous solutions.

\footnotetext{
${ }^{a}$ Departamento de Química Inorgánica, Facultat de Química, Universidad de Valencia, Burjasot, Spain. Fax: 96354432; Tel: 963544584

${ }^{b}$ Departamento de Química Inorgánica, ICMOL, Facultat de Química, Universidad de Valencia, Burjasot, Spain. E-mail: juan.frias@uv.es; Fax: 963544322; Tel: 963544403

${ }^{c}$ Departamento de Cardiología, Hospital Universitario de La Princesa, Madrid, Spain

$\dagger$ Electronic supplementary information (ESI) available: General experimental, DRX, TEM micrograph, fluorescence experiments, lifetime measurements and relaxivity. See DOI: 10.1039/b704650b
}

Iron oxides such magnetite $\left(\mathrm{Fe}_{3} \mathrm{O}_{4}\right)$, maghemite $\left(\gamma-\mathrm{Fe}_{2} \mathrm{O}_{3}\right)$ or other ferrites, which are insoluble in water have been studied as contrast agents for magnetic resonance imaging (MRI). These nanoparticles are coated with polymers such as dextran or carboxydextran. ${ }^{7}$ Due to the low sensitivity of MRI, boehmite nanoparticles may amplify the signal as the carrier can be loaded with contrast agents. To our knowledge, this is one of the first one-pot reported procedures for attaching lanthanide macrocyclic complexes to the surface of boehmite nanoparticles.

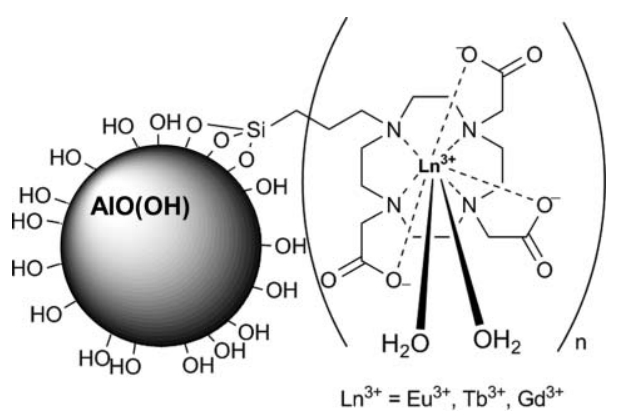

Tris-tert-butyl ester of DO3A was prepared under mild alkylation conditions according to Parker and co-workers ${ }^{8}$ Reaction of DO3A ester with (3-iodopropyl)trimethoxysilane afforded a mixture of unreacted DO3A triester, functionalized DO3A and (3-iodopropyl)trimethoxysilane. To this mixture of products were added the nanosized particles of boehmite $(\gamma$-AlOOH). Supported aluminium-DO3A triester nanoparticles were separated from DO3A by centrifugation. Hydrolysis of the tert-butyl groups of DO3A was accomplished using trifluoroacetic acid. Lanthanide complexes were prepared by reaction of the supported ligands with the appropriate chloride salts (see ESI $\dagger$ ). The supported complexes were characterized by a variety of experimental analyses. Elemental analysis revealed that boehmite nanoparticles loaded $2.81 \times 10^{-4}, 2.17 \times 10^{-4}$ and $1.57 \times 10^{-4}$ moles of gadolinium, terbium and europium per gram of sample. These values are similar to other loadings obtained before for different organic substrates. ${ }^{5}$ These numbers are translated into 800-1500 ions of lanthanide per nanoparticle considering an average diameter of $18 \mathrm{~nm}$ per nanoparticle of boehmite.

Fluorescence spectra of colloidal solutions containing $\mathrm{Eu}^{3+}$ and $\mathrm{Tb}^{3+}$ complexes $(\mathrm{Eu}-$ Boeh and $\mathrm{Tb}-\mathrm{Boeh})$ grafted in the nanoparticle were recorded upon direct excitation at 396 and $355 \mathrm{~nm}$, respectively. The europium complex supported on boehmite nanoparticles showed the typical transitions of europium complexes, especially intense was the band $\Delta J=2$ which is particularly sensitive to the chemical environment. The terbium complex in 

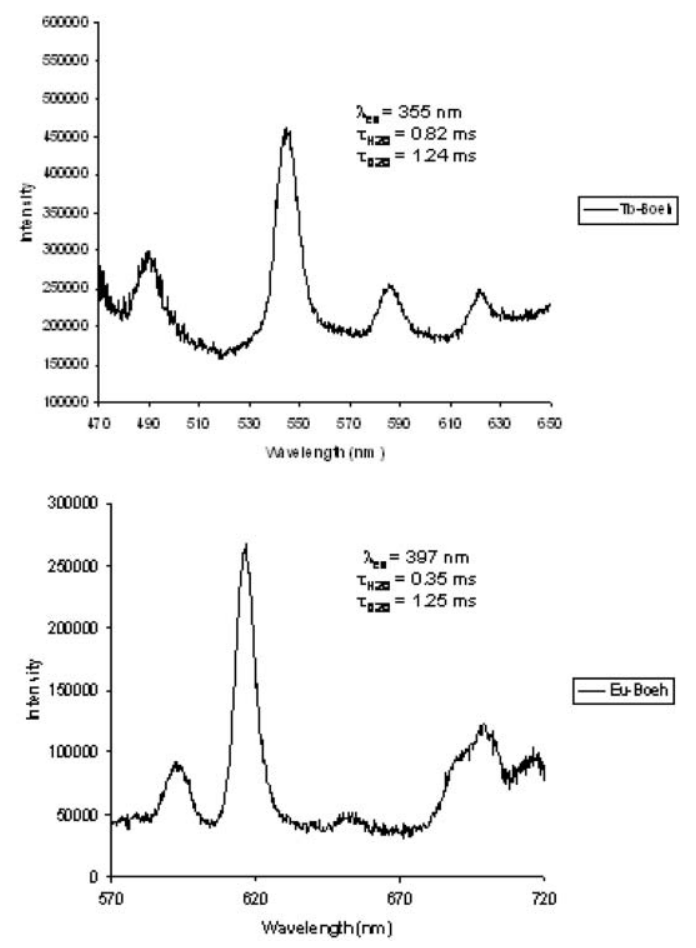

Fig. 1 Emission spectra of Tb-boehmite (top) and Eu-boehmite (bottom) in water.

boehmite shows distinctive luminescence at 480-630 nm consisting of four emission bands, assigned to the respective transitions from ${ }^{5} \mathrm{D}_{4}$ state to the ground state ${ }^{7} \mathrm{~F}_{J}(J=3,4,5,6)$ (Fig. 1). The number of coordinated water molecules in $\mathrm{Eu}-\mathrm{Boeh}$ and $\mathrm{Tb}-\mathrm{Boeh}$ was assessed by measuring the lifetime of the $\mathrm{Eu}^{5} \mathrm{D}_{0}$ and $\mathrm{Tb}{ }^{5} \mathrm{D}_{4}$ excited states in $\mathrm{H}_{2} \mathrm{O}$ and $\mathrm{D}_{2} \mathrm{O} .{ }^{9}$ Such measurements were done at several $\mathrm{pHs}$ with or without $\mathrm{NaCl}$. The results were consistent with the presence of two bound water molecules $(q=2)$. Addition of $\mathrm{NaCl}$ to $\mathrm{Eu}-\mathrm{Boeh}$ or $\mathrm{Tb}-\mathrm{Boeh}$ at different $\mathrm{pHs}$ did not produce any change in the fluorescence intensity. Although LnDO3A derivatives are susceptible to interact with carbonate, titrations of $\mathrm{Eu}-$ Boeh nanoparticles with $\mathrm{NaHCO}_{3}$ at pH 7.4 in 0.1 M HEPES resulted in no changes in the $\Delta J=2 / \Delta J=1$ ratio. $^{10}$

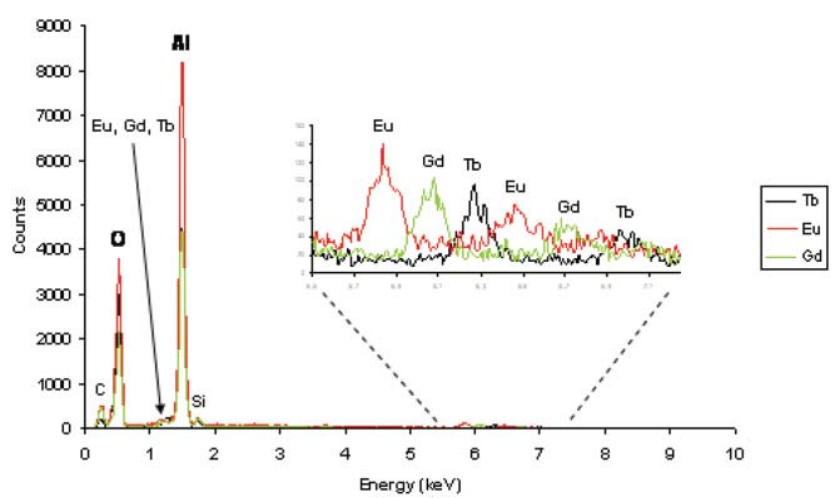

Fig. 2 EDX spectra for the boehmite nanoparticles loaded with $\mathrm{Eu}, \mathrm{Tb}$ or Gd complexes.

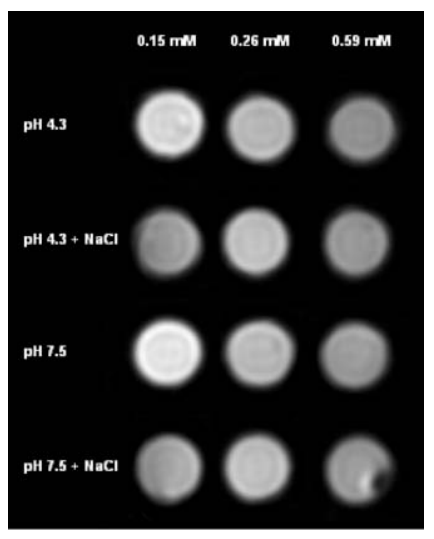

Fig. $3 T_{1}$ map of Gd-boehmite acquired at $1.5 \mathrm{~T}$ (TE $8.8 \mathrm{~ms}$, TR $10000 \mathrm{~ms}$, and TI $200 \mathrm{~ms}$ ) at different pHs.

The energy-dispersive X-ray (EDX) spectra (Fig. 2) of the $\mathrm{Eu}^{3+}$, $\mathrm{Tb}^{3+}$, and $\mathrm{Gd}^{3+}$ modified nanoparticles evidence the attachment of the DO3A to the surface.

Using this method, the average qualitative analysis of the samples provided 1: 1 lanthanide : silicon atomic ratio which supports that all grafted cyclen was complexed to the lanthanides.

Magnetic resonance imaging of the gadolinium sample was performed on a whole body 1.5 T GE Excite MR scanner (63 MHz, $25{ }^{\circ} \mathrm{C}$ ) (Fig. 3). Inversion-recovery spin echo pulse sequences (TE $8.8 \mathrm{~ms} / \mathrm{TR} 10000 \mathrm{~ms} / \mathrm{TI} 50-4000 \mathrm{~ms}$ ) were used for $T_{1}$ measurements. The values of $T_{1}$ were plotted against several gadolinium concentrations obtained by ICP-MS measurements. The relaxivity measured at $\mathrm{pH} 4.3$ and 7.5 provided, respectively, values of 1.75 and 1.49 in the absence of $\mathrm{NaCl}$ and 1.33 and $1.32 \mathrm{mM}^{-1} \mathrm{~s}^{-1}$ in the presence of $\mathrm{NaCl}$. These low relaxivities suggest a poor water exchange dynamics, however at $\mathrm{pH} 2$ relaxivity increases to a relatively high value $\left(11.71 \mathrm{mM}^{-1} \mathrm{~s}^{-1}\right)$ suggesting that the protonation state of the $-\mathrm{OH}$ groups at the surface plays an important role in water exchange dynamics. From the same experiment a $T_{1}$ value of $1560 \mathrm{~ms}$ was measured for boehmite.

In conclusion, we have modified the surface of boehmite nanoparticles with an easy one-pot reaction by appending a silane that contains a cyclen moiety. These nanoparticles are able to complex lanthanide ions in aqueous solution and hold promise as potential new contrast agent media for MR applications.

Financial support from the Ministerio de Educación y Ciencia, grants CTQ2006-15672-C05-01 and CTQ2006-15672-C05-04 is acknowledged. We would like to thank Prof. Miguel A. Miranda and Jana Rohacova (Instituto de Tecnología Química, UPVCSIC) for their help in recording lifetime measurements.

\section{Notes and references}

1 K. G. Thomas and P. V. Kamat, Acc. Chem. Res., 2003, 36, 888-898. 2 M. Qhobosheane, S. Santra, P. Zhang and W. H. Tan, Analyst, 2001, 126, 1274-1278

3 S. H. Chen and K. Kimura, Langmuir, 1999, 15, 1075-1082.

4 R. Aucejo, J. Alarcón, C. Soriano, M. C. Guillem, E. García-España and F. Torres, J. Mater. Chem., 2005, 15, 2920-2927.

5 R. Aucejo, P. Díaz, E. García-España, J. Alarcón, E. Delgado-Pinar, F. Torres, C. Soriano and M. C. Guillem, New J. Chem., 2007, 31, $44-51$. 
6 (a) P. Caravan, J. J. Ellison, T. J. McMurry and R. B. Lauffer, Chem. Rev., 1999, 99, 2293-2352; (b) The Chemistry of Contrast Agents in Medical Magnetic Resonance Imaging, ed. A. E. Merbach and E. Toth, Wiley, New York, 2001.

7 C. Corot, P. Robert, J.-M. Idée and M. Port, Adv. Drug Delivery Rev., 2006, 58, 1471-1504.

8 S. Aime, A. Barge, M. Botta, J. A. K. Howard, R. Kataky, M. P. Lowe, J. M. Moloney, D. Parker and A. S. de Sousa, Chem. Commun., 1999, 1047-1048
9 A. Beeby, I. M. Clarkson, R. S. Dickins, S. Faulkner, D. Parker, L. Royle, A. S. de Sousa, J. A. G. Williams and M. Woods, J. Chem. Soc., Perkin Trans. 2, 1999, 493-503.

10 (a) J. I. Bruce, R. S. Dickins, L. J. Govenlock, T. Gunnlaugsson, S. Lopinski, M. P. Lowe, D. Parker, R. D. Peacock, J. J. B. Perry, S. Aime and M. Botta, J. Am. Chem. Soc., 2000, 122, 9674-9684; (b) Y. Bretonniere, M. J. Cann, D. Parker and R. Slater, Org. Biomol. Chem., 2004, 2, 1624-1632.

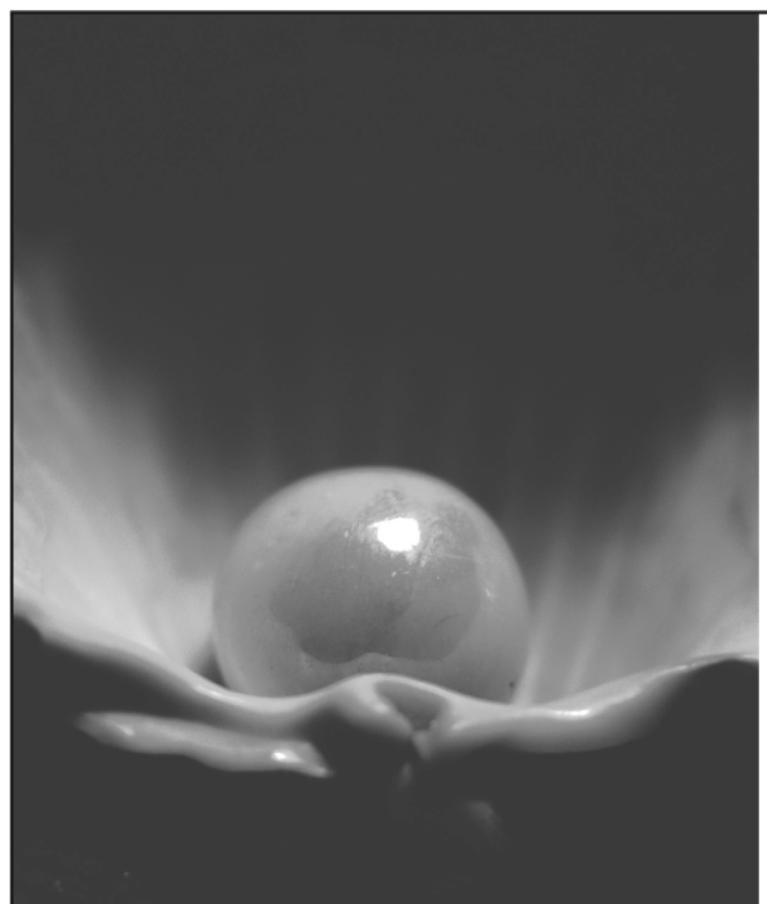

\section{Looking for that SPQCial research paper from applied and technological aspects of the chemical sciences?}

TRY this free news service:

\section{Chemical Technology}

- highlights of newsworthy and significant advances in chemical technology from across RSC journals

- free online access

- updated daily

- free access to the original research paper from every online article

- also available as a free print supplement in selected RSC journals.*

${ }^{*}$ A separately issued print subscription is also available.

Registered Charity Number: 207890

\section{RSCPublishing}

www.rsc.org/chemicaltechnology 